\title{
Pengaruh Model Pembelajaran Kooperatif Tipe STAD Berbasis Mind mapping Terhadap Keterampilan Berpikir Kritis Sisw Pada Konsep Gerak Lurus di SMA Negeri 1 Ampibabo
}

\author{
Sisriawan Lapasere, Marungkil Pasaribu dan Yusuf Kendek \\ sisriawan.lapasere23@gmail.com \\ Program Studi Pendidikan Fisika FKIP Universitas Tadulako \\ Jl. Soekarno Hatta Km. 9 Kampus Bumi Tadulako Tondo Palu - Sulawesi Tengah
}

\begin{abstract}
Abstrak - Penelitian ini bertujuan untuk menguji signifikansi perbedaan keterampilan berpikir kritis antara kelompok siswa yang diberi perlakuan dengan model pembelajaran kooperatif tipe STAD berbasis mind mapping dengan kelompok siswa yang diberi perlakuan dengan model pembelajaran kooperatif tipe STAD pada konsep gerak lurus siswa kelas X SMA Negeri 1 Ampibabo. Metode yang digunakan adalah eksperimen kuasi dengan equivalent preetest-posttest design. Populasi penelitian ini adalah seluruh siswa kelas X SMA Negeri 1 Ampibabo. Teknik pengambilan sampel adalah purposive sampling. Kelas X A sebagai kelas eksperimen dan kelas X D sebagai kelas kontrol. Instrumen keterampilan berpikir kritis siswa adalah tes berbentuk essay yang telah divalidasi oleh validator ahli yaitu Dr. Marungkil Pasaribu, M.Sc. Hasil analisa data diperoleh rerata skor kelas eksperimen adalah 18,61 , standar deviasi 2,97 dan daya serap 74,44\% berada pada kategori kritis, untuk kelas kontrol diperoleh rerata skor yaitu 15,51, standar deviasi 2,57 dan daya serap 62,04\% berada pada kategori cukup kritis dari jumlah total skor yaitu 25. Berdasarkan uji hipotesis (uji-t dua pihak) diperoleh $t_{\text {hitung }}=3,74$ dan $t_{\text {Tabel }}=t_{(1-1 / 2 a)}$ pada taraf nyata $a=0,05$ dan $d k=\left(n_{1}+n_{2}-2\right)=36+37-2=71$, diperoleh $t_{0,95(71)}=2,00$. Harga thitung $(3,74)$

$>$ tabel $(2,00)$ maka $\mathrm{H}_{1}$ diterima dan $\mathrm{H}_{0}$ ditolak. Hasil ini menyatakan bahwa terdapat pengaruh model pembelajaran kooparatif tipe STAD berbasis mind mapping terhadap keterampilan berpikir kritis pada konsep gerak lurus siswa kelas X SMA Negeri 1 Ampibabo.
\end{abstract}

Kata Kunci: Kooperatif tipe STAD, Mind mapping, Keterampilan Berpikir Kritis.

\section{PENDAHULUAN}

Dalam menghadapi MEA (Masyarakat Ekonomi Asean), Indonesia masih harus meningkatkan kualitas dan mutu dari berbagai aspek, terutama pendidikan. Pendidikan mengemban peran penting dalam membangun sumber daya manusia yang kompetitif dan mampu bersaing dengan negara lain. Oleh karena itu untuk menyambut MEA, pendidikan harus mampu mempersiapkan sumber daya manusia (SDM) yang terampil, peka dan kritis dalam menghadapi tantangan maupun perubahanperubahan yang akan terjadi di dunia pendidikan mendatang.

Pendidikan berhubungan erat dengan pembelajaran. Pembelajaran dapat diartikan sebagai suatu upaya mengkondisikan siswa untuk dapat belajar secara efektif. Pembelajaran umumnya dilakukan di sekolah-sekolah. Di sekolah menengah atas (SMA), mata pelajaran fisika merupakan salah satu mata pelajaran yang wajib. Dimana tujuan pembelajaran fisika bukan hanya menyediakan peluang kepada siswa untuk belajar tentang fakta-fakta dan teori-teori, tetapi juga mengembangkan kemampuan melalui latihan bertindak atas dasar pemikiran yang kritis.

Dalam pembelajaran IPA Fisika, proses dan produk sama pentingnya serta tidak dapat dipisahkan. Agar dapat mengajarkan mata pelajaran fisika dengan efisien dan efektif sudah banyak digunakan model-model pembelajaran yang kreatif dan inovatif. Salah satunya model pembelajaran kooperatif tipe STAD. Model pembelajaran kooperatif tipe STAD adalah model pembelajaran yang melibatakan siswa berperan aktif dalam bentuk kelompok-kelompok kecil, sehingga siswa dapat berinteraksi satu sama lain dalam memecahkan suatu permasalahan[1].

Hanya saja model pembelajaran kooperatif tipe STAD penekanannya terletak pada pencapaian kemajuan pada tahap akhir. Hal ini mengakibatkan tingkat ke efektifan dalam mengembangkan kemampuan berpikir kritis siswa belum maksimal [2]. Walaupun demikian, metode STAD sudah terbukti mampu meningkatkan hasil belajar siswa [3-6]

Kemampuan berpikir kritis merupakan kompetensi yang harus dimiliki oleh siswa, berpikir kritis telah terbukti mempersiapkan siswa dalam berpikir pada berbagai disiplin ilmu karena berpikir kritis merupakan kegiatan kognitif yang dilakukan siswa dengan cara membagi-bagi cara berpikir dalam kegiatan nyata dengan memfokuskan pada membuat keputusan mengenai apa yang diyakini atau dilakukan [7]. Salah satu metode yang dapat meningkatkan keterampilan siswa dalam berpikir 
kritis adalah metode mind mapping. Metode mind mapping adalah metode mencatat kreatif yang memudahkan kita mengingat banyak informasi, meningkatkan kemampuan siswa dalam berpikir karena memadukan dan mengembangkan potensi kerja otak, sehingga perhatian terpusat pada subjek serta mampu mengembangkan cara pengaturan pikiran secara terperinci[8].

Model pembelajaran kooperatif tipe STAD dapat menciptakan pembelajaran yang menarik sehingga siswa dapat dengan mudah memahami materi yang disampaikan, memberi respon yang positif, pembelajaran menjadi lebih menyenangkan, dan membentuk siswa yang mampu bekerjasama dalam kelompok sehingga bisa meningkatkan hasil belajar. Novriansyah[9] menyatakan tahap-tahap model pembelajaran kooperatif tipe STAD: Menyampaikan tujuan dan memotivasi siswa; (2) Menyajikan informasi; (3) Mengorganisasikan siswa kedalam kelompok-kelompok belajar; Membimbing kelompok bekerja dan belajar; Evaluasi; dan (6) Memberikan penghargaan.

Metode mind mapping yang dikombinasikan dengan model pembelajaran dapat meningkatkan hasil pembelajaran siswa. seperti penelitian yang dilakukan oleh Dantes, dkk[10] bahwa metode mind mapping yang dikombinasikan dengan ekspositori dapat meningkatkan hasil belajar siswa.

Berdasarkan penjelasan di atas, maka peneliti mengkomparasikan keterampilan berpikir kritis antara kelompok siswa yang diberi perlakuan model pembelajaran kooperatif tipe STAD berbasis mind mapping dengan kelompok siswa yang diberi perlakuan model pembelajaran kooperatif tipe STAD. Materi yang diajarkan dalam penelitian ini yaitu gerak lurus, dan pelaksanaannya di SMA Negeri 1 Ampibabo.

\section{METODE PENELITIAN}

Penelitian yang digunakan adalah jenis penelitian dengan rancangan eksperimen kuasi (quasiexperimental design)[11].

Desain penelitian yang digunakan yaitu the equivalent pretest-posttest design[8]. Desain penelitian yang digunakan dapat dilukiskan seperti pada tabel 1 .

TABEL 1 DESAIN PENELITIAN

\begin{tabular}{cccc}
\cline { 3 - 4 } Kelompok & Pre- test & Perlakuan & Post-test \\
Eksperimen & $\mathrm{O}_{1}$ & $\mathrm{X}$ & $\mathrm{O}_{1}$ \\
Kontrol & $\mathrm{O}_{1}$ & & $\mathrm{O}_{1}$
\end{tabular}

\footnotetext{
Keterangan:

$X$ : Model pembelajaran kooperatif tipe STAD berbasis mind mapping

$\mathrm{O}_{1}$ : Tes awal dan tes akhir
}

Penelitian dilakukan di SMA Negeri 1 Ampibabo. Populasinya adalah seluruh siswa kelas $X$ tahun pelajaran 2015/2016 yang terdiri dari 6 kelas. Sampel dalam penelitian ini diperoleh secara purposive sampling yaitu kelas XA yang berjumlah 36 siswa sebagai kelas eksperimen yang diberikan perlakuan model pembelajaran kooperatif tipe STAD berbasis mind mapping dan kelas XD yang berjumlah 37 siswa sebagai kelas kontrol yang diberikan perlakuan model pembelajaran kooperatif tipe STAD. Teknik pengambilan sampel yang digunakan adalah purposive sampling, yaitu teknik penentuan sampel dengan pertimbangan tertentu.

Instrumen yang digunakan untuk melihat keterampilan berpikir kritis siswa. Tes yang digunakan berupa tes essay sebanyak 5 item soal yang dilakukan sebanyak dua kali pengujian, yaitu pada tahap awal sebelum perlakuan (pre-test) dan tahap akhir setelah perlakuan (post-test). Tes ini sebelumnya di validasi oleh validator ahli

Data yang diperoleh dari penelitian ini selanjutnya diolah dengan menggunakan uji statistik berupa uji normalitas (Chi kuadrat), uji homogenitas (Fisher), dan uji hipotesis (uji-t dua pihak).

\section{HASIL DAN PEMBAHASAN}

\section{A. Hasil Penelitian}

Hasil pengolahan data pre-test dan post-test untuk masing-masing kelas yaitu kelas eksperimen dan kelas kontrol, diperoleh nilai maksimum, nilai minimum, nilai rata-rata dan simpangan baku seperti terlihat pada Tabel 2 .

TABEL 2 DESKRIPSI SKOR TES KETERAMPILAN BERPIKIR KRITIS SISWA

\begin{tabular}{|c|c|c|c|c|}
\hline \multirow{2}{*}{ Uraian } & \multicolumn{2}{|c|}{ Pre-te $\underline{t}$} & \multicolumn{2}{|c|}{ Post-t ist } \\
\hline & Eksperimen & Kontrol & Eksperimen & Kontrol \\
\hline $\begin{array}{l}\text { Sampel } \\
(\mathrm{n})\end{array}$ & 36 & 37 & 36 & 37 \\
\hline $\begin{array}{l}\text { Skori } \\
\text { maksimum }\end{array}$ & 14 & 13 & 24 & 21 \\
\hline $\begin{array}{l}\text { Skor } \\
\text { minimum }\end{array}$ & 3 & 2 & 13 & 10 \\
\hline $\begin{array}{l}\text { Skor rata- } \\
\text { rata }\end{array}$ & 8,36 & 7,24 & 18,61 & 15,51 \\
\hline $\begin{array}{l}\text { Standar } \\
\text { deviasi }\end{array}$ & 2,92 & 2,84 & 2,93 & 2,96 \\
\hline
\end{tabular}

Hasil pengujian normalitas menggunakan uji Chikuadrat dengan kriteria penerimaan X2Hitung < $\mathrm{X}^{2}$ tabel, taraf signifikansi $\mathrm{a}=0,05$ dan derajat kebebasan $\mathrm{dk}=\mathrm{k}-3$. Berdasarkan hasil perhitungan skor pre-test nilai $\chi^{2}$ hitung untuk kelas eksperimen adalah 3,71 dan untuk kelas kontrol adalah 5,44 dengan $\chi^{2}$ tabel sebesar 7,81. Data tersebut disajikan pada tabel 3 . 
TABEL 3 HASIL UJI NORMALITAS PRE-TEST KELAS EKSPERIMEN DAN KELAS KONTROL

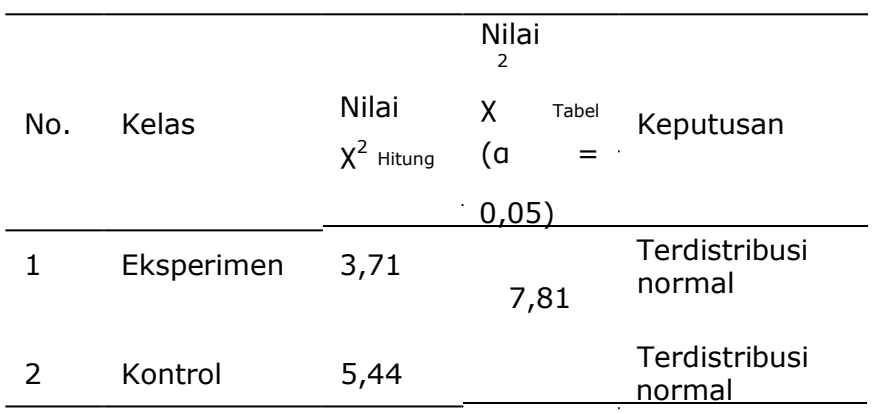

Berdasarkan hasil uji normalitas pada Tabel 3 diketahui nilai $\mathrm{x} 2$ Hitung $<$ X2tabel sehingga dapat dinyatakan kedua kelas berasal dari populasi yang terdistribusi normal.

Uji homogenitas pada penelitian ini menggunakan uji statistik Fisher (Uji F) dengan taraf signifikansi a $=0,05$. Uji homogenitas dilakukan untuk melihat apakah data berasal dari varians yang sama atau tidak. Data tersebut disajikan pada tabel 4.

TABEL 4 HOMOGENITAS DUA VARIANS TES AKHIR (PRE TEST) KELAS

\begin{tabular}{ccc}
\multicolumn{3}{c}{ EKPERIMEN DAN KELAS KONTROL. } \\
\hline Varians hitung & NilaiFtable $(a=0,05)$ & Keputusan \\
\hline 1,06 & 3,07 & $\begin{array}{c}\text { Data } \\
\text { homogen }\end{array}$ \\
\hline
\end{tabular}

Berdasarkan hasil uji homogenitas pada Tabel 4 dengan taraf signifikansi $(a=0,05)$, dari data tersebut terlihat bahwa $F_{\text {hitung }}(1,06)<F_{\text {tabel }}$ $(3,07)$ maka berdasarkan kriteria pengambilan keputusan dapat dinyatakan bahwa tidak terdapat perbedaan varians antara kelas eksperimen dan kelas kontrol atau dengan kata lain varians antara kelas eksperimen dan kelas kontrol adalah sama atau homogen.

Uji t yang digunakan untuk hipotesis ini adalah uji-t dua pihak. Uji ini digunakan untuk memastikan apakah hipotesis yang diajukan dapat diterima atau ditolak. Uji t tersebut diperoleh berdasarkan data skor pre-test dan post-test. Data tersebut disajikan pada tabel 5 dan 6.

TABEL 5 UJI BEDA RATA-RATA (DUA PIHAK) PRE-TEST KELAS EKSPERIMEN DAN KELAS KONTROL

\begin{tabular}{|c|c|c|c|c|c|}
\hline \multirow{3}{*}{ No. } & \multirow{3}{*}{ Kelas } & Nilai rata- & \multirow{3}{*}{$\mathrm{t}$ hitung } & & \multirow{3}{*}{ Keputusan } \\
\hline & & rata ( $X$ & & & \\
\hline & & ) & & table & \\
\hline \multirow[t]{2}{*}{1} & Eksperimen & 8,36 & & & $\mathrm{H}_{0}$ \\
\hline & & & 1,66 & 2,00 & diterima \\
\hline 2 & Kontrol & 7,24 & & & \\
\hline
\end{tabular}

Berdasarkan data pada tabel 5 terlihat bahwa thitung $(1,66)<$ tabel $(2,00)$. Nilai thitung berada pada daerah penerimaan $\mathrm{H}_{0}$. Dengan demikian $\mathrm{H}_{0}$ diterima dan $\mathrm{H}_{1}$ ditolak. Hal ini menyatakan
TABEL 6 UJI BEDA RATA-RATA (DUA PIHAK) POST-TEST KELAS EKSPERIMEN

\begin{tabular}{|c|c|c|c|c|c|}
\hline & & Nilai & & $\mathrm{t}$ & \\
\hline No. & Kelas & rata-rata & $\mathrm{t}$ hitung & table & Keputusan \\
\hline 1 & Eksperimen & 18,61 & 3,74 & 2,00 & $\begin{array}{c}\mathrm{H}_{1} \\
\text { diterima }\end{array}$ \\
\hline
\end{tabular}

Hasil uji beda rata-rata setelah diberi perlakuan dapat dilihat pada tabel 6 . Berdasarkan data pada tabel 6 thitung $(3,74)>$ tabel $(2,00)$. Hal ini berarti, nilai thitung berada diluar daerah penerimaan $\mathrm{H}$. Hasil ini menyatakan terdapat perbedaan keterampilan berpikir kritis antara kelas yang diberi perlakuan dengan model pembelajaran kooperatif tipe STAD berbasis mind mapping dengan kelas yang diberi perlakuan model pembelajaran kooperatif tipe STAD.

\section{B. Pembahasan}

Berdasarkan data hasil penelitian, dilakukan uji normalitas, homogenitas dan hipotesis untuk mengetahui keadaan awal siswa. Dari hasil uji normalitas, homogenitas dan hipotesis diperoleh data bahwa keadaan awal siswa yang dijadikan sampel adalah terdistribusi normal, homogen dan tidak ada perbedaan dari segi pengetahuan sehingga dapat digunakan untuk penelitian. Hasil analisis data pre-test untuk kelas eksperimen rerata skor yang diperoleh adalah 8,36 dengan standar deviasi 2,92 dan daya serap 33,44\% (sangat kurang kritis), sedangkan kelas kontrol rerata skor yang diperoleh adalah 7,24 dengan standar deviasi 2,84 dan daya serap 28,96\% (sangat kurang kritis). Dengan menggunakan uji-t dua pihak diketahui bahwa kedua kelas yang dijadikan sampel penelitian yaitu kelas eksperimen (XA) dan kelas kontrol (XD) memiliki kemampuan keterampilan berpikir kritis yang sama. Setelah diberikan perlakuan pada kedua kelas yang dijadikan sampel penelitian yaitu kelas eksperimen dengan model pembelajaran

kooperatif tipe STAD berbasis mind mapping dan

pada kelas kontrol dengan model pembelajaran kooperatif tipe STAD diperoleh rerata skor keterampilan berpikir kritis siswa pada materi gerak lurus yang ditunjukan dari hasil post-test

untuk kelas eksperimen adalah 18,61 dengan sebelum diberi perlakuan tidak terdapat perbedaan keterampilan berpikir kritis antara kelas XA (kelas eksperimen) dengan kelas XD (kelas kontol). 
standar deviasi 2,93 dan daya serap $74,44 \%$ (kritis) sedangkan kelas kontrol adalah 15,51 dengan standar deviasi 2,57 dan daya serap $62,04 \%$ (cukup kritis). Hasil ini menyatakan bahwa pembelajaran dengan menerapkan model pembelajaran kooperatif tipe STAD berbasis mind mapping lebih unggul dibandingkan model pembelajaran kooperatif tipe STAD saja. 
Secara kualitatif dari perhitungan daya serap menunjukkan bahwa di kedua kelas yaitu kelas eksperimen dan kelas kontrol terjadi peningkatan keterampilan berpikir kritis siswa dari keadaan awal tetapi dalam hal ini keterampilan berpikir kritis siswa kelas eksperimen lebih tinggi (sangat kurang kritis menjadi kritis) dibandingkan keterampilan berpikir kritis siswa pada kelas kontrol (sangat kurang kritis menjadi cukup kritis), hal ini disebabkan karena pada kelas eksperimen diberikan perlakuan dengan menerapkan model pembelajaran kooperatif tipe STAD berbasis mind mapping sedangkan pada kelas kontrol di berikan perlakuan dengan model pembelajaran kooperaif tipe STAD saja.

Komponen utama pada model pembelajaran kooperatif tipe STAD ini ada 6 tahapan. Di kedua kelas yang dijadikan sampel penelitian sama-sama menggunakan model pembelajaran kooperatif tipe STAD yang memenuhi 6 tahap tersebut hanya saja pada kelas eksperimen model pembelajaran kooperatif tipe STAD di kombinasikan dengan mind mapping sehingga sedikit berbeda dengan pembelajaran yang ada pada kelas kontrol tetapi perbedaannya hanya terletak pada proses dari tahapan pembelajaran yang ada pada kelas eksperimen.

Tahapan perlakuan yang membedakan kelas eksperimen dan kelas kontrol terletak pada fase ketiga dan ke empat. Pada fase ketiga yaitu mengorganisasikan siswa kedalam kelompokkelompok belajar. Pembentukan tim/kelompok terdiri dari 4-5 orang siswa yang mewakili seluruh bagian dari kelas dalam hal kinerja akademik, jenis kelamin, ras dan etnis. Dalam kelompok ini siswa dibagikan tugas diskusi kelompok didalamnya memuat materi yang diajarkan. Kedua kelas yang dijadikan sampel penelitian mendapat perlakuan yang sama hanya saja dalam tugas diskusi yang dilakukan di kedua kelompok bentuknya berbeda. Untuk kelas eksperimen tugas diskusi berupa gambaran singkat mengenai mind mapping. Siswa dilatih untuk mandiri dalam mengembangkan materi pokok yang telah diajarkan oleh peneliti. Setiap kelompok diberi kesempatan untuk mempresentasikan hasil kerja kelompoknya, sedangkan kelompok lain diberi kesempatan untuk menanggapi sedangkan untuk kelas kontrol diberikan tugas diskusi kelompok sehingga proses pembelajaran yang berlangsung kurang terarah dengan suasana kurang menyenangkan dan tegang.

Fase keempat yaitu membimbing kelompok bekerja dan belajar. Pada fase ini peneliti membimbing kelompok-kelompok yang dijadikan sampel penelitian yaitu kelas eksperimen dan kelas kontrol. Di kelas eksperimen peneliti membimbing para siswa dalam membuat mind mapping dengan menuliskan pokok bahasan yang akan dikembangkan menjadi beberapa cabang, diantara cabang-cabang tersebut harus berbeda warna agar terlihat bagus dengan visualisasii gambar yang menarik untuk dibaca sedangkan pada kelas kontrol peneliti membimbing para siswa dalam menyelasaikan tugas diskusi kelompok yang berisikan beberapa pertanyaan.

Dalam tahapan pada model pembelajaran kooperatif tipe STAD ini berpengaruh dalam meningkatkan indikator-indikator keterampilan berpikir kritis yaitu keterampilan menganalisis, keterampilan mensintesis, keterampilan mengenal dan memecahkan masalah, keterampilan menyimpulkan dan keterampilan mengevaluasi atau menilai tetapi tidak terlalu signifikan dibandingkan dengan model pembelajaran kooperatif tipe STAD yang dikombinasikan dengan mind mapping.

Penerapan mind mapping pada model pembelajaran kooperatif tipe STAD memiliki kelebihan seperti (1) mengaktifkan seluruh otak, memungkinkan kita fokus pada pokok bahasan, (2) membantu menunjukkan hubungan antara bagian-bagian informasi yang saling terpisah, (3) memberi gambaran yang jelas pada keseluruhan dan perincian, dan (4) menyenangkan untuk dilihat, dibaca, dicerna dan diingat. Sehingga secara kuantitatif yang diperoleh dari hasil analisis data, rata-rata perubahan keterampilan berpikir kritis siswa dikelas ekseperimen lebih tinggi dari pada kelas kontrol. Hal ini menunjukkan bahwa pemberian model pembelajaran kooperatif tipe STAD berbasis mind mapping lebih berpengaruh terhadap keterampilan berpikir kritis siswa dibandingkan dengan pembelajaran kooperatif tipe STAD yang diberikan di kelas kontrol pada konsep gerak lurus.

\section{KESIMPULAN DAN SARAN}

Berdasarkan penelitian yang dilakukan, dapat disimpulkan terdapat pengaruh yang signifikansi model pembelajaran kooperatif tipe STAD berbasis mind mapping terhadap keterampilan berpikir kritis pada konsep gerak lurus siswa kelas $X$ SMA Negeri 1 Ampibabo. Dengan data kuantitatif yang diperoleh dari perhitungan uji hipotesis post-test yaitu uji t dua pihak adalah nilai thitung $(3,74)>$ ttabel $(2,00)$. Hal ini berarti, nilai thitung berada diluar daerah penerimaan $\mathrm{HO}$.

Berdasarkan kesimpulan ada beberapa saran yang dapat dikemukakan:(1) peneliti harus mengetahui karakteristik dan kemampuan setiap siswa agar pembagian kelompok merata dan kegiatan pembelajaran dapat terlaksana dengan baik, (2) peneliti dapat memperhitungkan waktu 
di setiap fase pembelajaran agar lebih efisien, karena waktu menjadi salah satu kendala dalam proses pembelajaran, (3) kepada seluruh tenaga pendidik khususnya guru fisika kiranya dapat mempertimbangkan pembelajaran kooperatif tipe STAD berbasis mind mapping sebagai salah satu alternatif dalam usaha untuk meningkatkan keterampilan berpikir kritis siswa.

\section{DAFTAR PUSTAKA}

[1] Fitrina. (2013). Pengaruh Kooperatif Tipe STAD Terhadap Hasil Belajar Siswa Kelas V Sdn 36. Universitas Tanjung Pura: Pontianak

[2] Slavin, R.E. (2005). Cooperative Learning Teori, Riset dan Praktik. London: Allymand Bacon

[3] D. Setianingsih, A. Ramadhan, dan Y. Gagaramusu. (2015). Meningkatkan Pemahaman Konsep BagianBagian Tumbuhan Melalui Pembelajaran Kooperatif Model Stad Pada Siswa Kelas IV SDN 02 Laantula Jaya Kec. Wita Ponda Kab. Morowali. Jurnal Kreatif Online, Vol. 3 No. 2, 41-52.

[4] Hasmiati, Baharuddin, dan Sukayasa. (2016). "Penerapan Model Pembelajaran Kooperatif Tipe STAD Untuk Meningkatkan Hasil Belajar Siswa Pada Materi Pengurangan Bilangan Sampai Dengan 500 Kelas II SDN 2 Tinigi Kecamatan Galang Kabupaten Tolitoli". Jurnal Kreatif Online, Vol. 4 No. 3, 195-205.

[5] L. S. Rahayu, A. Ramadhan, dan N. Laganing. (2015). Meningkatkan Kemampuan Mengidentifikasi Hewan Berdasarkan Makanannya Melalui Pendekatan Kooperatif
Tipe STAD di Kelas IV SDN Bumi Harapan Kecamatan Wita Ponda Kabupaten Morowali Jurnal Kreatif Online, Vol. 3 No. 2, 23-30.

[6] T. Masoyang, B. Saneba, dan A. Palimbong (2014). "Meningkatkan Hasil Belajar Pada Pembelajaran PKn Melalui Kooperatif Tipe Student Teams Achievement Division (STAD) Di Kelas $\mathrm{V}$ SDN Inpres Popisi Kecamatan Peling Tengah". Jurnal Kreatif Online, Vol. 2 No. $128-141$.

[7] Sudiarta, I.G. (2009). Pengembangan Pembelajaran Berpendekatan Tematik Berorientasi Pemecahan Masalah Matematika Terbuka Untuk Mengembangkan Kompetensi Berpikir Divergen, Kritis, Dan Kreatif. Jurnal Pendidikan dan Pengajaran UNDIKSHA. 2 (4):373-392.

[8] Ristiasari, T., Bambang, P dan Sri, S (2012). Model Pembelajaran Problem Solving Dengan Mind Mapping Terhadap Kemampuan Berpikir Kritis Siswa. Unnes Journal of Biology Education, Vol. 1, No. 3, Hal 34-40.

[9] Novriansyah, B. (2013). Penerapan Strategi 'PQ4R' Dan Potofolio Pada Model Pembelajaran Kooperatif Tipe STAD Sebagai Upaya Meningkatkan Penguasaan Kosa Kata Bahasa Arab Siswa Kelas XII Bahasa MAN 1 Model Bengkulu. MAN 1 Model Palu: Tidak diterbitkan

[10] Dantes, N., Widiana, I.W dan Arsana, I.M.R. (2014). Pengaruh Metode Ekspositori Yang Dikombinasikan Dengan Mind Mapping Terhadap Hasil Belajar IPA. Universitas Pendidikan Ganesha: SingarajaSukmadinata, N. (2010). Metode Penelitian Pendidikan. Bandung: PT. Remaja Rosdakarya

[11] Sugiyono. (2006). Metode Penelitian Pendidikan Pendekatan Kuantitatif, Kualitatif, dan R\&D. Bandung: Alfabeta 